\title{
PERANCANGAN DESAIN SISTEM BASIS DATA PENGELOLAAN ASET (Studi Kasus: Universitas Galuh Ciamis)
}

\author{
Dadan Mulyana ${ }^{1}$ \\ ${ }^{2}$ Magister Sistem Informasi Bisnis STIMIK LIKMI Bandung \\ e-mail : ${ }^{1}$ dadanm0712@gmail.com \\ Bacilius Agung Suburdjati ${ }^{2}$ \\ ${ }^{3}$ Magister Sistem Informasi Bisnis STIMIK LIKMI Bandung \\ e-mail : 'basnagung@gmail.com
}

\begin{abstract}
Abstrak
Universitas Galuh adalah perguruan tinggi swasta yang memiliki 7 Fakultas, 1 Program Pascasarjana, Lembaga Penelitian dan Pengabdian Kepada Masyarakat (LPPM), Badan Penjaminan Mutu Internal (BPMI), Perpustakaan dan Kantor Kerjasama. Dari banyaknya tempat yang ada di Universitas Galuh itu menjadi permasalahan yang harus dihadapi dalam manajemen pengelolaan aset. Pengelolaan aset tersebut masih mengandalkan peran dari manusia yang tidak bisa melakukan pendataan aset yang sangatlah banyak. Jika orang tersebut lupa akan menjadi masalah apalagi terkait jenis aset yang melakukan pembayaran dan jika terlambat akan dikenakan sanksi ataupun denda. Penelitian ini untuk memudahkan dalam menghitung jumlah aset dan pencatatan perawatan aset tersebut. Aplikasi pengelolaan aset ini akan bebasis web-based dengan menggunakan bahasa pemerograman php dan MySql sebagai basis datanya. Hasil dari penelitian ini berupa desain basis data yang nantinya akan di implemtasikan pada website yang bisa diakses oleh pengelola aset yang akan melakukan pencatatan perawatan aset dan juga sebagai pengingat akan perawatan aset-aset yang berada di Universitas Galuh.
\end{abstract}

Kata Kunci: Sistem Informasi, Pengelolaan Aset, ERD, Desain Basis Data

Abstract

Universitas Galuh is a private university that has 7 faculties, 1 Postgraduate Program, Research and Community Service Institute (LPPM), Internal Quality Assurance Agency (BPMI), Library and Cooperation Office. From the many places in Galuh University, it becomes a problem that must be faced in asset management. The management of these assets still relies on the role of human beings who can not do a lot of asset collection. If the person forgets it will be a problem especially related to the type of asset that made the payment and if it is too late will be subject to sanctions or fines. This research is to facilitate in calculating the number of assets and recording the maintenance of these assets. This asset management application will be web-based free by using php and MySql programming languages as its database. The result of this research is a database design that will be implemtasikan on the website that can be accessed by asset managers who will record asset maintenance and also as a reminder of the maintenance of assets located at the University of Galuh.

Keywords :Information System, Asset Management, ERD, Database Design 


\section{PENDAHULUAN}

Sistem informais pengelolaan aset merupakansistem informasi manajemen pendataanasset inventaris secara terintegrasi seluruh gedung yang ada di Universitas Galuh dalam rangka melaksanakan tertib administrasi pengelolaan dan pendataan barang. Dengan adanya sistem pengelolaan aset ini Intansi dapat menentukan apa saja aset-aset yang telah tersdia serta dapat pemeliharaan suatu barang dengan perawatan yang teratur. Dalam hal ini sistem pengelolaan aset iniakan dibuat dapat di akses dimana saja dan dapat mempermudah pekerjaan dalam melakukan pencatatan tentang aset-aset yang dimiliki intansi.

Universitas Galuh adalah perguruan tinggi swasta yang berada di kabupaten ciamis dengan banyaknya mengelola aset dalam bidang akademik, sepert: meja, kursi, papan tulis, proyektor, komputer, alat-alat praktikum mahasiswa dan yang lainnya.

\section{TINJAUAN PUSTAKA}

\section{A. Teknologi informasi}

Terdapat beberapa definisi tentang teknologi informasi.Menurut Haag dan Ken [1] Teknologi informasiadalah seperangkat alat yang membantu anda bekerja dengan informasi dan melakukan tugas-tugas yang berhubungan dengan pemrosesan informasi. Sedangkan menurut Martin

Teknologi informasi tidak hanya terbatas pada teknologi komputer (perangkat keras dan perangkat lunak) yang digunakan untuk memproses dan menyimpan informasi, melainkan juga mencakup teknologi komunikasi untuk mengirimkan informasi. Menurut William dan Sawyer,

Teknologi Informasi adalah teknologi yang menggabungkan komputasi (komputer) dengan jalur komunikasi berkecepatan tinggi yang membawa data, suara dan video [2]. Dari beberapa pengertian tersebut, terlihat bahwa secara implisit maupun eksplisit teknologi informasi tidak sekedar berupa teknologi komputer, namun juga mencakup teknologi telekomunikasi. Dengan kata lain, teknologiinformasi adalah gabungan antara teknologi computer dan teknologi telekomunikasi.

\section{B. Aplikasi}

Aplikasi memiliki beberapa pengertian. MenurutFebrian, Aplikasi merupakan program siap pakai yangdigunakan manusia dalam melakukan pekerjaan menggunakan komputer [3]. Sedangkan menurut Hartono Jogiyanto, Aplikasi merupakan program yang berisikan perintah-perintah untuk melakukan pengolahan data [4]. Jogiyanto menambahkan, aplikasi secara umum adalah suatu proses dari cara manual yang di transformasikan ke komputer dengan membuat system atau program agar data diolah lebih berdaya guna secara optimal. Menurut Dhanta, aplikasi adalah software yang dibuat oleh suatu perusahaan komputer untuk mengerjakantugas-tugas tertentu, misalnya Microsoft Word dan Microsoft Excel [5]. Anisiyah memiliki definisi tersendiri mengenai aplikasi. Menurut anisiyah, aplikasi adalah penerapan, penggunaan atau penambahan data [6]. Berdasarkan pengertian-pengertian diatas, maka dapat disimpulkan bahwa aplikasi adalah suatu perangkat lunak 
yang berjalan diatas suatu sistem operasi dimana perangkat lunak tersebut berisi perintahperintah yang berfungsi untukmelakukan berbagai pekerjaan atau tugas tertentu yangberhubungan dengan pengolahan data.

\section{Bahasa Pemrograman}

Tahun 1991 sekelompok insinyur SUN dipimpin olehPatrick Naughton dan james Gosling ingin merancang bahasakomputer untuk perangkat konsumer seperti cable TV Box.Karena perangkat tersebut tidak memiliki banyak memori,bahasa harus berukuran kecil dan mengandung kode yang

mudah dimengerti. Karena platform pada setiap prosesorberbeda, maka bahasa harus bebas dari platform manapun. [7]. Kebutuhan untuk fleksibilitas, kecil, mudahdimengerti dan kode yang netral terhadap platform mengantartim mempelajari implementasi Pascal yang pernah dicoba.Niklaus Wirth, pencipta bahasa Pascal telah merancang bahasaportabel yang menghasilkan intermediate code untuk mesinhipotesis. Mesin ini disebut mesin maya (virtual machine).Kode ini kemudian dapat digunakan di sembarang mesin yangmemiliki interpreter. Proyek Green menggunakan mesin mayauntuk mengatasi masalah utama yaitu netral terhadaparsitektur mesin.Karena orang-orang pada proyek Green berbasis $\mathrm{C}++$ dan bukan Pascal maka kebanyakan sintaks diambil dari $\mathrm{C}++$.

sebuah kendali jarak jauh yang sangat cerdas. Pada saat yangsama, implementasi WWW dan Internet sedang mengalamiperkembangan pesat. Anggota dari proyek Green jugamenyadari bahwa JAVA dapat digunakan pada pemrogramaninternet, maka penerapan selanjutnya mangarah menjaditeknologi yang berperan di web.

\section{Basis Data}

Menurut Conolly, Basis data adalah kumpulan datayang terbagi dan terhubung secara logika dan merupakandeskripsi dari data yang dirancang untuk memnuhi kebutuhan informasi [8]. Menurut C.J Date, Basis data terdiri daribeberapa kumpulan data tetap yang digunakan oleh sistemaplikasi untuk diberikan kepada perusahaan [9]. MenurutKusrini Basis data adalah sekumpulan data yang memilikihubungan satu sama lain atau memiliki relasi [10].Data adalah fakta mengenai objek, orang dan lain-lain.Data dapat dinyatakan dengan nilai. Berdasarkan pengertianpengertian tersebut diatas, maka dapat disimpulkan bahwabasis data merupakan suatu kumpulan data yang memilikihubungan satu sama lain dan dibuat atau dirancang dengantujuan memenuhi kebutuhan akan informasi dari suatuorganisasi atau perusahaan.

Basis data memiliki beberapa komponen antara lain :

\section{Entitas}

Entitas merupakan penerapan integritas data pada tabelbasis data agar setiap baris pada suatu entitas bersifat unikyang disebut dengan primary key sehingga data yang satu dengan yang lainnya berbeda

\section{Atribut}


Setiap entitas pasti memiliki atribut yangmendeskripsikan karakteristik dari entitas tersebut. Penentuanatau pemilihan atribut yang relevan bagi sebuah entitasmerupakan hal yang penting dalam merancang sebuah modeldataKusrini Basis data adalah sekumpulan data yang memilikihubungan satu sama lain atau memiliki relasi [10].

\section{E. Database Management System (DBMS)}

Menurut Kristanto, Database Management Systemadalah kumpulan data yang saling berkaitan bersama dengan program untuk dikelola [11]. DBMS terdiri dari basis data danperangkat lunak pengelola data yang digunakan untukmenambah, menghapus, melihat dan mengubah data.Sedangkan menurut Connoly dan Begg, DatabaseManagement System adalah suatu sistem perangkat lunak yangmemungkinkan pengguna untuk mendefinisikan membuat,memelihara dan mengatur akses ke basis data [8].Berdasarkan definisi definisi tersebut, kita dapatmenyimpulkan bahwa Database Management System adalahsebuah perangkat lunak yang dibuat untuk mengelola basisdata. Contoh DBMS antara lain : MySQL, Oracle, SQL Serverdan lain-lain.

\section{F. MySQL}

MySQL merupakan sebuah perangkat lunak pembuatdan pengelola basis data yang bersifat open source dimanaperangkat lunak ini berjalan disemua platform baik linuxmaupun Windows. MySQL merupakan program yang dapatdigunakan untuk aplikasi multiuser (banyak pengguna).MySQL didistribusikan secara gratis dibawah lisensi

GPL (General Public Licence ). Setiap orang bebas untukmenggunakan MySQL namun tidak boleh dijadikan produkturunan yang bersifat komersial.

\section{G. Perancangan Basis Data}

Menurut Conolly dan Begg, perancangan basis dataadalah proses untuk menciptakan desain basis data yang akanmendukung kebutuhan dan tujuan suatu perusahaan [8].

Perancangan basis data dibagi menjadi tiga tahap, antara lain :

\section{Conceptual Database Design}

Conceptual database design adalah suatu prosesmembangun suatu model berdasarkan informasi yang didapatdari perusahaan atau organisasi dan digunakan olehperusahaan atau organisi itu sendiri tanpa pertimbangan

perencanaan fisik. Pada tahap ini langkah-langkah yang dapat dilakukan adalah mengidentifikasi entitas, mengidentifikasi relasi, mengidentifikasi danmenghubungkan atribut dengan entitas atau relasi,menentukan atribut domain, menentukan atribut candidate keydan primary key, mempertimbangkan penggunaan enhancemodeling concepts dan mengecek adanya redudansi data.

\section{METODELOGI PENELITIAN}




\subsection{Teknik Wawancara}

Teknik ini dilakukan dengan cara diskusi dan tanya jawab kepada pihak-pihak terkait dengan aset tetap. Hal ini lebih difokuskan kepada bagian logistik dan bagian akuntansi. Bagian logistik yang merupakan diberi kewenangan penuh untuk mengelola dan mengawasi aset tetap.

\subsection{Teknik Observasi}

Pada teknik ini melakukan pemantauan langsung terhadap objek-objek aset tetap. Perolehan data dilakukan dengan data primer dikarenakan belum tersedianya informasi pencatatan semua aset yang ada di Universitas Galuh.

\subsection{Dokumentasi}

Data yang diperoleh dari dokumen-dokumen yang dimiliki oleh entitas yang berhubungan dengan masalah penelitian, untuk memperoleh data berupa daftar aset tetap.

\subsection{Teknik Analisa Data}

Pada teknik ini penulis menggunakan teknik kualitatif (deskriptif) dengan menggunakan alat bantu perancangan sistem seperti Data Flow Diagram (DFD) dan Entity Relationship Diagram (ERD).

\section{Hasil dan Pembahasan}

Mendesain basis data diharapkan dapat menjelaskan semua aktivitas dengan baik sehingga hasil yang diinginkan sesuai dengan keinginan pengguna dan diharapkan pula dapat meminimalkan kekurangan dan kelemahan sistem yang ada saat ini. Dengan adanya desain basis data diharapkan akan :

a. Meningkatkan kecepatan informasi yang dihasilkan dan efisiensi dalam pengolahan data. $b$. Memperoleh keakuratan data yang dapat dipertanggungjawabkan.

c. Memperkecil persentase kerusakan (hilang atau hancur) data. Dengan desain basis data terhadap aset tetap diharapkan akan mampu mengolah aset dimulai dari proses permintaan aset sampai proses inventaris dan termonitornya keberadaan dan kondisi aset.

Menggunakan basis data berguna dalam penyimpanan data dengan jumlah data relative banyak sehingga dapat mempermudah penyimpanan, pencarian, pengubahan serta penghapusan data. Perancangan sistem merupakan mendesain langkah-langkah operasi dalam proses pengolahan data dan prosedur untuk mendukung operasi sistem. Adapun langkahlangkah dalam perancangan sistem pada sistem informasi aset tetap ini adalah mempergunakan model Data Flow Diagram (DFD) dan model Entity Relationship Diagram (ERD).

\subsection{Model Data Flow Diagram (DFD)}


Dalam penjabarannya Data Flow Diagram (DFD) terdiri dari Diagram Konteks dan Diagram Zero . Berikut Diagram Konteks untuk sistem informasi aset tetap pada Universitas Galuh.

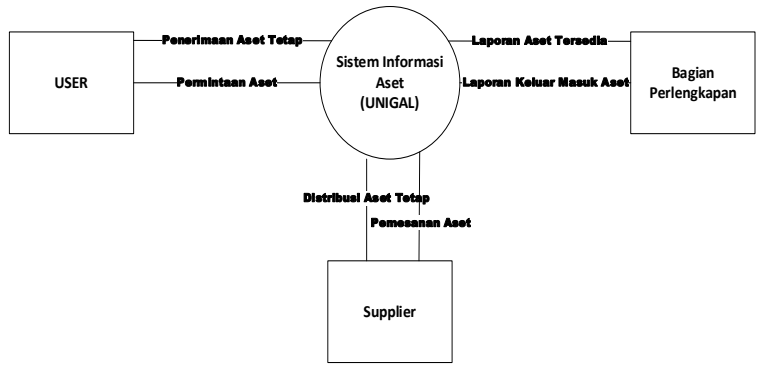

Gambar 4.1 Model Data Flow Diagram

Berikut DFD Level 0 untuk sistem informasi aset tetap di Univerasitas Galuh Ciamis.

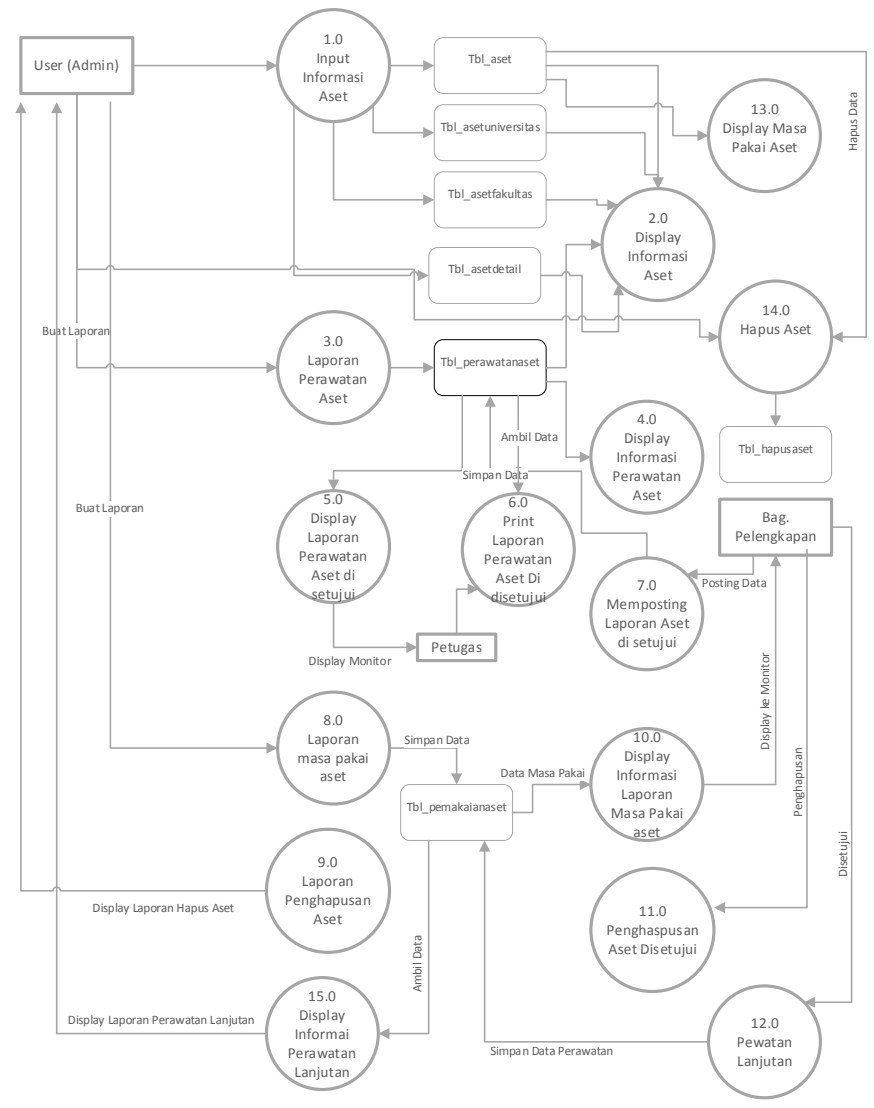

Gambar 4.1 Data Flow Diagram Level 0

\subsection{Model Entity Relationship Diagram}

Diagram Entity Relationship merupakanjaringan yang menggunakan susunan data yangdisimpan dari sistem secara abstrak. Diagram EntityRelationship ini ditemukan oleh Chen Tahun1976.Tujuan dari Entity Relationship adalah untukmenunjukkan objek data dan relationship yang adapada objek tersebut. Disamping itu Model ER inimerupakan salah satu alat untuk perancangandalam basis data. Dalam pengembangan sisteminformasi aset tetap 


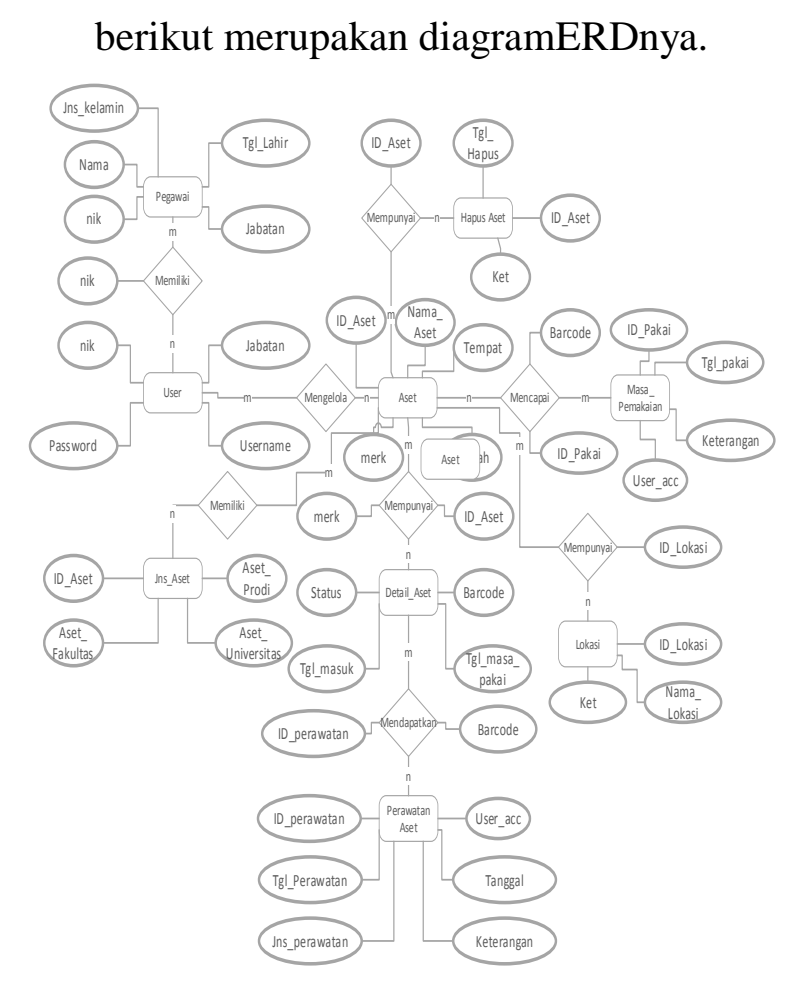

Gambar 4.2 Model Entity Realtionship Diagram

Dari ERD di atas untuk perangcangan database bagian aset agar dapat dengan mudah dalam menglola aset di Univesitas Galuh.

\subsection{Struktur Kode Aset}

Pemberian struktur kode pada aset di Universitas Galuh bertujuan agar dapat memberikan informasi lengkap mengenai aset yang ada. Informasi tersebutmencerminkan detail aset, lokasi aset, masa pemakaian aset dan lain-lain.

Dua digit kedua merupakan struktur kode asetuntuk menunjukkan kode Lembaga.Tiap Fakultas memiliki aset dalam menunjang kegiatan operasional di Fakultasnya masingmasing. Kode tiapdepartemen dijabarkan sebagai berikut :

Tabel 1. Kode Lembaga

\begin{tabular}{|l|l|}
\hline Kode Fakultas & Nama Fakultas \\
\hline 01 & Keguruan \\
\hline 02 & Fisip \\
\hline 03 & Teknik \\
\hline 04 & Pertanian \\
\hline 05 & Pasca Sarjana \\
\hline 06 & Ekonomi \\
\hline 07 & Fikes \\
\hline 08 & BPMI \\
\hline 09 & LPPM \\
\hline
\end{tabular}


Satu digit ketiga merupakan struktur kode asetuntuk menunjukkan kode lokasi padabangunan gedung. Kode lokasi bangunangedung dijabarkan sebagai berikut:

Kode 1 untuk lokasi gedung Lantai

Kode 2 untuk lokasi gedungLembaga

Tabel 2. Kode Lokasi

\begin{tabular}{|l|l|}
\hline Kode Lokasi & Nama Lokasi \\
\hline 101 & Gedung FKIP \\
\hline 102 & Gedung Fisip \\
\hline 103 & Gedung Teknik \\
\hline 104 & Gedung Pertanian \\
\hline 105 & Gedung Pasca Sarjana \\
\hline 106 & Gedung Ekonomi \\
\hline 107 & Gedung Fikes \\
\hline 108 & Gedung BPMI \\
\hline 109 & Gedung LPPM \\
\hline
\end{tabular}

Dua digit keempat merupakan struktur kode asettetap untuk menunjukkan kode kategori assettetap. Kode kategori aset tetap dijabarkansebagai berikut :

Tabel 3. Kategori Aset

\begin{tabular}{|c|l|}
\hline Kode Kategori Aset & Nama Kategori Aset \\
\hline 01 & Bangunan \\
\hline 02 & Sarana dan Prasarana \\
\hline 03 & Peralatan Lab \\
\hline 04 & Peralatan Kantor \\
\hline 05 & $\begin{array}{l}\text { Peralatan dan Perabot } \\
\text { Ruang Kelas }\end{array}$ \\
\hline 06 & Peralatan Olahraga \\
\hline 07 & Peralatan Dapur \\
\hline
\end{tabular}

Adapn Tiga digit kelima merupakan struktur kodeaset tetap untuk menunjukkan kode sub darikategori aset tetap. Kode sub dari kategoriaset tetap dijabarkan sebagai berikut:

Tabel 4. Kode Sub Kategori Aset

\begin{tabular}{|c|c|}
\hline Kode Sub & Nama Sub \\
\hline Kategori Aset & Kategori \\
\hline 501 & AC \\
\hline 502 & Infokus \\
\hline 503 & Komputer \\
\hline 504 & Meja Kerja \\
\hline
\end{tabular}




\begin{tabular}{|c|c|}
\hline 505 & Meja Kelas \\
\hline 505 & Whiteboard \\
\hline 506 & Lemari \\
\hline
\end{tabular}

\section{KESIMPULAN DAN SARAN}

\subsection{Kesimpulan}

Kesimpulan dari penelitin ini pada pengelolaan aset di Universitas Galuh yang akan dirancang agar bisa digunakan dalam pekerjaan:

1. Pelaporan secara berkala yang dapat dimonitoring oleh pimpinan pemegang aset agar dapat terpelihara dengan baik.

2. Tersedianya informasi aset di Universitas Galuh yang bisa diakses dimana saja karena berbasis web-based.

3. Perancangan ini belum diuji coba sehingga belum diketahui kinerja sistem dan kesalahan dalam pengelolaan aset di Universitas Galuh.

\subsection{Saran}

Saran dari penelitiaan ini sebagai berikut:

1. Perlunya diuji coba pada sistem pengelolaan aset yang telah dibuat

2. Adanya kebijakan tentang pengelolaan aset oleh pihak yang mempunya hak dalam pengelolaan aset

3. Perlunya penelitian lebih lanjut untuk di implementasikan yang berbasis web-based.

\section{DAFTAR PUSTAKA}

[1] Haag, S and Keen P. 1996. Information Tecnology, Tomorrow's Advantage Today. New York : McGrawHill, 1996.

[2] Zonyfar, C., \& Maharina, Z. M. \& Barack, E.(2020). Student enrollment: Data mining using naïve bayes algorithm. Journal of Advanced Research in Dynamical and Control Systems, 12(7), 1077-1083.

[3] Martin, E. 1999. Managing Information TechnologyWhat Managers Need to Know (3rd. Ed). New Jersey :Pearson Education International, 1999.

[4] Febrian, Jack. 2006. Kamus Komputer dan TeknologiInformasi. Bandung : INFORMATIKA, 2006.

[5] Hartono, Jogiyanto. 2005. Analisis \& Desain SistemInformasi Pendekatan Terstruktur Teori dan PraktekAplikasi Bisnis. Yogyakarta : Penerbit ANDI, 2005.

[6] Dhanta, Rizky. 2009. Pengantar Ilmu Komputer.Surabaya : INDAH, 2009.

[7] Anisyah. 2000. Analisa dan Desain Sistem Informasi. Yogyakarta : Penerbit ANDI, 2000. 
Dadan Mulyana, Bacilus Agung Suburdjati

[8] Wu C, Thomas. 2010. An introduction to objectoriented programming with Java. New York, USA :s.n., 2010.

[9] Zonyfar, C., Baihaqi, K. A., \& Pertiwi, A. B. (2020). Pixel value differencing and modulus function method for embedded message in digital images. International Journal of Psychosocial Rehabilitation, 24(7), 3379-3385.

[10] Connoly, T.M. dan Begg, C.E. 2002. DatabaseSystems: A Pratical Approach to Design,Implementation, and Management, edisi ke-3. Harlow :Addison-Wesley, 2002.

[11] C.J., Date. 2004. Pengenalan Sistem Basis Data(diterjemahkan oleh Carley Tanya). Jakarta : PT.Indeks Group Gramedia, 2004.

[12] C. Zonyfar, S. Sihabudin, and A. Khusaeri, "Peningkatan Kemampuan Siswa dalam Memanfaatkan Sumber Belajar di Internet Melalui Sosialisasi Edukasi Internet Cerdas, Sehat, dan Aman”, tribhakti, vol. 1, no. 1, pp. 17-20, Dec. 2019.

[13] S. . and C. Zonyfar, "Social Media Marketing and Brand Awareness for Millennial Generation”, J Arch.Egyptol, vol. 17, no. 1, pp. 131-140, Nov. 2020.

[14] Kusrini. 2007. Strategi Perancangan dan PengelolaanBasis Data. Yogyakarta : Penerbit Andi, 2007.

[11] Kristanto, Harianto. 2009. Konsep dan PerancanganDatabase. Yogyakarta : Penerbit ANDI, 2009. 